\title{
TALLADO Y DEMARCACIÓN: COMPOSICIONES TRANSPUESTAS ENTRE EL ROCK DE BRASIL Y DE ARGENTINA
}

\author{
Adrián Pablo Fanjul* \\ Universidade de São Paulo \\ São Paulo, São Paulo, Brasil
}

\begin{abstract}
Resumen: Abordamos, de modo comparativo entre discursividades brasileñas y argentinas, configuraciones para la representación de diversos tipos de entidades personales en la enunciación. Los casos analizados son composiciones poético-musicales, encuadradas en el campo del rock, transpuestas de un país al otro. Trabajamos a partir de un referencial teórico y metodológico ubicado en el análisis discursivo-enunciativo. Observamos las transformaciones que se producen, en el paso de las composiciones de una discursividad y una lengua a la otra, en lo referente al contorno de las figuras y de las voces representadas en la enunciación. Encontramos, en las producciones argentinas, una tendencia al refuerzo de esos contornos y en las producciones brasileñas una mayor permeabilidad con el entorno representado.
\end{abstract}

Palabras-clave: Persona en la enunciación. Discursividad en el rock. Estudios comparados entre Brasil y Argentina.

\section{INTRODUCCIÓN}

Este trabajo se encuadra en un proyecto de investigación más general sobre discursividades en la música urbana de Brasil y de Argentina, específicamente sobre los subcampos que en cada uno de esos dos países han recibido el nombre de "rock nacional". La investigación tiene una perspectiva comparativa y se realiza en el marco teórico del análisis

\footnotetext{
* Doutor em Linguística pela UNESP. Email: adrianpf@yahoo.com.

${ }^{1}$ El proyecto cuenta con apoyo del Conselho Nacional de Desenvolvimento Científico e Tecnológico (CNPq). En cuanto a la denominación "subcampo", será desarrollada en la sección siguiente.
} 
discursivo-enunciativo, articulando conceptos y categorías analíticas que se explicitarán en la segunda sección.

Focalizaremos en este artículo la cuestión de las instancias de persona en los diversos niveles de representación que la enunciación y el discurso movilizan, problematizando la delimitación de entidades personales de diferente carácter y alcance involucradas en esos niveles. Lo haremos a partir de una contraposición entre composiciones de rock que fueron adaptadas de un país al otro, transponiendo la letra a la otra lengua. Consideraremos dos temas que sufrieron ese tipo de adaptación, uno de Argentina a Brasil y otro de Brasil a Argentina. "Viernes 3 AM" fue grabada por primera vez en 1979 por el grupo Seru Girán, tercero en la carrera de Charly García, autor del tema. Casi veinte años después la grabó Paralamas do Sucesso en versión de Herbert Vianna para el disco Hey $\mathrm{Na}$ $\mathrm{Na}$ (1998), manteniendo el título en castellano. La segunda composición es "O tempo não pára", de Cazuza en su etapa solista, divulgada en el LP en vivo del mismo nombre que apareció en 1988. La entonces naciente banda argentina Bersuit Vergarabat la adaptó y registró en su primer disco, Y punto, de 1991, en versión de Gustavo Cordera y Carlos Martín. Las dos letras y sus versiones están en el anexo ubicado al final del artículo.

La sección siguiente presentará nuestro marco teórico $\mathrm{y}$ metodológico abordando primero lo relativo a las instancias personales y su relación con la constitución de la subjetividad en el discurso, y posteriormente algunas especificidades sobre la enunciación en el campo estudiado, así como algunas aclaraciones sobre el tipo de hecho de transposición considerado en relación a los estudios sobre traducción. En los ítemes tercero y cuarto realizamos el análisis de los dos casos que nos ocupan, y en el último presentamos conclusiones en relación con las discursividades que han atravesado el campo del rock.

\section{PRESUPUESTOS TEÓRICO-METODOLÓGICOS 2.1 SUBJETIVIDAD, SERES DEL ENUNCIADO, PERSONA}

Para un amplio sector de los estudios discursivos y enunciativos, entre los cuales nos ubicamos, el sujeto del discurso, al menos en uno de 
sus niveles de abordaje, no es una entidad estable a lo largo del enunciado sino un lugar a ser llenado, lugar constituido en el propio proceso discursivo y sin continuidad en el enunciado, ya que este último puede ser atravesado, en diferentes puntos, por diversas posiciones de sujeto. A partir de la postulación que, al terminar la década del 60, Michel Foucault realizara en La arqueología del saber (FOUCAULT, 2007, p. 121-126), se puede ver al sujeto como la posición que se ocupa para formular lo que se formula, una función vacía, determinada por las relaciones del enunciado con otros enunciados en series o dominios delimitables. Desde la corriente francesa del análisis del discurso cuyo principal referente fue Michel Pêcheux, va siendo establecido un diálogo, que podríamos denominar como de adopción polémica, con la teorización de Foucault, explicitado, entre otras obras, en un texto crucial de 1979 (PÊCHEUX, 1997) y, de un modo más convergente, en escritos de los años 80 (PÊCHEUX, 2011) ${ }^{2}$. En las importantes proyecciones que tuvo la obra de Pêcheux en Brasil, que dieron lugar a una verdadera (y multifacética) escuela de análisis del discurso, la noción de "posición de sujeto", se halla muy extendida, y con una clara inspiración foucaultiana, como puede verse, por ejemplo, en Orlandi (1988 y 1990) o Guimarães (1989 y 2005). Así, hablar desde una posición de sujeto es hacerlo desde una región del interdiscurso (GUIMARÃES, 2005, p. 30) relacionable con la dimensión ideológica.

Otro orden de fenómenos, que entra en relación con el anterior pero es diferente, es el de las voces representadas en el enunciado y por la enunciación, lo que con Guimarães (2005, p. 23) podríamos llamar “agenciamiento enunciativo". Desde cuando Benveniste (1971, p. 85) situó los "indicios de persona" como centro movilizador de todas las formas de la lengua en el funcionamiento que se pone en marcha por el proceso enunciativo, muchas han sido las propuestas para describir y analizar las diversas figuras personales cuya representación se complejiza por las formas de discurso referido, por la ficcionalización, por los soportes

\footnotetext{
2 Pêcheux adopta y reformula la noción de "formación discursiva" de Foucault, lo que no quiere decir que comparta integralmente su visión sobre el sujeto. Sobre los modos como la concepción althusseraina de la ideología y del sujeto afectaron la relación de Pêcheux y colaboradores con la teorización de Foucault, recomendamos la lectura de Gregolin (2004) y de la producción última del propio Pêcheux en 1982 (PÊCHEUX, 2002).
} 
mediáticos y por las muchas formas de presencia del discurso "otro" en el enunciado. Destacamos, entre otras, la distinción entre "locutor" y "enunciador" en el abordaje polifónico de la enunciación por Ducrot (2001), así como su recategorización por Guimarães (2005, p. 11-31) en función de "lugares sociales de decir", relacionados con papeles distinguibles en el funcionamiento social, político y cultural, y "lugares de decir", en los que se borra la implantación-histórico-social del locutor. Esos lugares se cruzan, de modo a veces poco diferenciado, con las entidades textualmente estabilizadas por la interlocución representada en lo que, con Maingueneau (2001 y 2008) llamaremos "escenografía enunciativa": locutores, interlocutores representados con diferentes grados de nitidez, personajes.

Nuestro trabajo parte de la observación de todas esas figuras representadas en el enunciado y de su modo de articulación y delimitación en torno del decir y sus lugares. Creemos que investigar recurrencias y tendencias para esas configuraciones, en un género o en un campo discursivo en el cual también se puedan reconocer posicionamientos subjetivos recurrentes es revelador, ya que el agenciamiento enunciativo no es una mera forma que vehicule sentidos o ideologías sin afectar su orientación en relación a una memoria del decir. Y si, como en nuestro caso, esa investigación se realiza de modo comparado entre alteridades separadas por la lengua y la nacionalidad, la contraposición de tendencias y predominios para determinadas configuraciones permite alcanzar conclusiones que provean una base sólida, desde la especificidad de las categorías del discurso, para los estudios socioculturales comparados.

\subsection{ENUNCIACIÓN EN EL ROCK, CONTORNOS Y NUESTRA INVESTIGACIÓN}

Como para otros géneros de la cultura de masas o de la llamada "música popular", creemos que para el rock es adecuada la caracterización que Díaz (2005), basándose en la noción de "campo" en Bourdieu (1989), le atribuye como "subcampo" de la producción y circulación de bienes culturales. Eso significa, entre otras cosas, que también presenta una propiedad fundamental de los campos, como es la disputa de legitimidad 
por el decir. Considerar que haya un decir roquero no debe significar caer en la ilusión monoglósica de pensarlo como el decir de un posicionamiento, de un lugar estable de constitución de sujetos. El subcampo que el rock ha ido conformando está atravesado por las muchas divergencias en su casi medio siglo de existencia, en que varias tradiciones han sido generadas, contestadas, defenestradas y/o recreadas alrededor de los muchos objetos de su discursividad.

Una de las recurrencias que encontramos en medio de esa heterogeneidad podemos identificarla con lo que Díaz (2005, p. 154-167) caracteriza como "diferencia disidente". Desde el punto de vista enunciativo, podemos verla como la escenificación de posicionamientos presentados como opuestos a una racionalidad - que no deja de serle complementaria - expuesta como dominante. La contraposición se realiza de diversas formas: el tópico de llegar a ver lo que otros no ven, la diferenciación respecto de un colectivo o de un contramodelo conforme, la instalación un lugar de decir que puede aparecer como de "saber" o de exaltación de un "no saber", pero que se proclama como revelador, y varios otros. Las voces de la diferencia disidente están marcadas por la contradicción entre el padecimiento y el goce que tal posicionamiento conlleva. Es muy adecuada al respecto de esa contradicción (aunque no compartamos su generalización a todo el subcampo) esta descripción del crítico literario argentino Monteleone (1992, p. 33)

Todo enunciado rocker es reconocido como enunciado de delincuencia. Palabra lacerada de un cuerpo que va en cana, palabra pronunciada en la hora detenida de un toque de queda; pero también palabra gozosa, en la fiesta de la fugaz resistencia y en el ritmo disruptor del cuerpo rocker.

Inclusive en composiciones que llevan sus objetos y su mundo representado al plano de lo íntimo, como ocurre por momentos en las que aquí analizaremos, también se manifiestan variantes de ese posicionamiento.

En cuanto a la representación de instancias personales en su materialidad verbal, o sea, en su letrística, en el rock ocurren las variadas 
posibilidades escenográficas que se observan en otros géneros ligados a la forma canción ${ }^{3}$ : desde soliloquios a grados moderados de ficcionalización o narrativización (pequeñas crónicas), con posibilidad de recibir inflexiones de otros géneros inclusive no artísticos, como proclamas, plegarias y otros. Esas posibilidades dan lugar a la instalación de diversas voces representadas e inclusive, en los casos en que hay un cierto grado de narrativización, de cuasi-personajes. Para todas esas voces, géneros tan performáticos como el rock actualizan notablemente la intercambiabilidad, por incorporación, con el par intérprete/oyente. Aclaramos que consideramos aquí "incorporación" a partir de una de las funciones que atribuye Maingueneau (2001, p. 140) a ese proceso en la relación entre fiador y coenunciador: la constitución de un cuerpo, el de la comunidad imaginaria que participa de la fruición de la obra. Creemos que, por incluir entre sus principales condiciones de circulación el recital y el canto colectivo, el rock es un género en que ese proceso resulta particularmente central.

Nos viene interesando, en nuestras investigaciones, la consideración de cómo se representa la relación y la delimitación ser/entorno para las figuras puestas en la escenografía enunciativa y/o para las voces en las que estas toman cuerpo. Creemos que es un factor relacionado con modos de representar la conflictividad, y que por eso es productivo observarlo, en un dominio de géneros y posicionamientos análogos, contraponiendo dos formaciones sociohistóricas diferentes (en nuestro caso, Brasil y Argentina en sus espacios urbanos contemporáneos). Así, en un trabajo anterior (FANJUL, 2005), se indagó, en composiciones del rock de ambos países de las décadas del 80' y del 90', casos en que se representa al héroe en relación con un entorno hostil en un conflicto de alcance colectivo, encontrando tendencias diferenciadas para cada país. En las composiciones brasileñas se destacaba una tendencia a representar la inferioridad relativa del héroe y su no control o no percepción del entorno, ambas como refuerzo precisamente de su heroicidad, mientras que en los casos argentinos predominaba una representación del héroe en intento de alcanzar

\footnotetext{
${ }^{3}$ En Tatit (2003, p. 9), la canción es definida como una forma poético-musical caracterizada por una progresión melódica con reiteración. Esa forma puede ser manifestada por géneros muy diversos.
} 
un dominio perceptivo del entorno y un cierre sobre su propio espacio en un movimiento que llamamos "endocéntrico".

En este trabajo nos ocuparemos de un aspecto de la enunciación relacionado con el ser representado, que analizaremos como contorno tallado por un decir. Usamos la metáfora del tallado precisamente porque de los varios aspectos en que la presencia de un ser puede observarse nos interesa cómo se delimita, en su decir o en el decir que lo construye, de los representados como complementarios de escena, solidarios y/o adversarios y cómo se delimita del entorno en la escenografía. Ese delimitarse tiene que ver con su propia emergencia como figura y su progresiva construcción en el enunciado, ya que como explica Maingueneau (2008, p. 70), la escenografía enunciativa no es un cuadro ya dado e independiente del discurso, sino que la propia enunciación lo va instalando. Por nuestra parte, y análogamente, creemos necesario también considerar que las dimensiones que ese autor propone como cronografía y topografía, así como la corporeidad que los seres adquieren en ellas tienen un carácter representacional, pero de una naturaleza diferente de la representación pictórica o teatral, precisamente porque están hechas de lenguaje verbal. No hay límites previos para su extensión ni planos o líneas previstos para su ocurrencia. La superposición, la indiferenciación, así como la cisión absoluta o la repetición indefinida son posibilidades dadas por el funcionamiento del lenguaje verbal para la representación de todo tiempo, espacio o cuerpo. Por eso lo que denominamos "contorno" no se procesa sólo mediante la descripción o atribución de cualidades y ubicaciones relativas, sino también por las marcas de argumentación y de todo tipo de semantismo. Así, creemos que las muchas formas de determinación, relaciones como adversatividad, causatividad, condición y otras intervienen en el tallado del ser puesto en escenografía cuando lo involucran en diversos roles.

En el caso de este trabajo, la contraposición no será entre temas musicales de cada país, sino entre composiciones que fueron adaptados de un país al otro, transponiendo la letra a la otra lengua. Cintrão (2007, p. 131-132) ubica la traducción de canciones en el conjunto de las prácticas que se denominan "traducción subordinada" porque sufren restricciones 
como consecuencia de la relación con un lenguaje no verbal, en su caso, el lenguaje musical. A su vez, por la proximidad que esas restricciones conllevan con las de la poesía, evalúa como adecuada la noción de "transposición creativa" propuesta por Jakobson (2001, p. 72) para definir el proceso que de hecho tiene lugar en la versión de la poesía a otra lengua. Creemos que es el tipo de proceso que ocurre en el material que analizamos. A la vez, consideramos que las restricciones que ese proceso conlleva pueden explicar el distanciamiento respecto de la forma presente en la lengua de partida, pero de ninguna manera explican la selección de una forma entre las muchas que cabrían en determinado lugar de un verso cantado en la lengua de llegada. Por lo tanto, creemos que, para cada uno de los lugares de la cadena intradiscursiva en los que vemos un indicio de las delimitaciones de entidades personales que aquí estudiamos, podrían haber ocurrido formas que se integrasen a otro efecto en la construcción de la escena, y no vemos la emergencia de ninguno de los indicadores específicos que observaremos como consecuencia inexorable de las restricciones de la práctica traductora.

Intentaremos mostrar en la próxima sección que, en el paso de estas composiciones a su versión otra, los contornos tallados para los seres representados sufren transformaciones. Y que hay cierta regularidad en esas transformaciones, que nos permite percibir la adecuación a lo que aparece como una expectativa en el campo del rock de cada país en relación con los seres y sus entornos.

\section{EL TALLADO Y SUS LASCAS}

"Viernes 3 AM" apareció en el segundo LP de Seru Girán, La grasa de las capitales (1979). En varios aspectos ese disco puede verse como un punto de referencia histórico. En su tema inicial y homónimo introduce, por momentos de modo paródico, ritmos que invitan al movimiento corporal, cosa extremamente infrecuente en el rock argentino de su época, y que prefigura lo que será una fuerte tendencia en los años posteriores. La obra inicia también un viraje fuertemente crítico en relación con el "estado de cosas" en el país, en un momento en que sectores importantes de las clases medias comienzan a manifestar una difusa disconformidad. No alude 
directamente a la dictadura, pero sí al clima de mediocridad reinante en el campo cultural y en los medios.

Sin embargo, todavía incluye expresiones de la etapa más lóbrega en la poética de Charly García. Persiste la familiaridad con diferentes formas de la muerte, el tono y la atmósfera melancólica de los mundos creados que una generación naturalizó ya antes de la dictadura, a través de temas como "Rasguña las piedras" (1973), casi todos los del LP Instituciones (1974) o "Nena" (1975, grabado después como "Eiti Leda" en el primer LP de Seru, en 1978). "Viernes 3 AM" es claramente una de esas expresiones, y su letra llega a aludir a un suicidio.

La figura representada en el centro de la escena está enunciada en segunda persona. En la grabación original difundida en La grasa de las capitales, a partir de la mención de la palabra "reloj" en el sexto verso de la primera estrofa, comienza a sonar al tic-tac de un reloj pulsera, que sólo cesa con la onomatopeya "Bang, bang, bang" en la mitad de la última estrofa.

El locutor, claramente ubicado en un lugar de saber, describe las actitudes y movimientos del tú y recuerda aspectos de un derrotero de vida atribuido a este último, marcado por diversas búsquedas infructuosas. Uno de los efectos de la peculiar articulación enunciativa es la construcción de un tú "en tela de juicio", que, sin voz, escucha la interpretación que de su propia persona y de su vida hace otro ser. El yo que se construye en esa voz "evaluadora" comparte con el tú la premisa de la necesidad de búsqueda de un espacio diferente e ilimitado, representado en la inmensidad "de un sol y de un mar" y en el rechazo a la seguridad sugerido por la "vida peligrosa" soñada. Ambos aparecen, de ese modo, relacionados con el universo de valores del campo roquero. Pero el saber escéptico del yo locutor condena la insuficiencia de ese deseo frente a lo que "en sí" no cambiará. Otro efecto de la enunciación construida es que los dos lugares, tanto el del yo como el del tú, están más disponibles para ser ocupados por el virtual alocutario que lo que estarían si se hubiese puesto en escena un personaje en $3^{a}$ persona. Se puede ocupar el lugar del desahuciado como escuchas de la canción, pero su entonación e "incorporación", con el valor que atribuimos a ese término en 2.2, nos desplazan al lugar de ese evaluador casi-juez. 
Los "bang" de la última estrofa sacan de escena al tú. Sólo quedan "hojas muertas que caen". El locutor pasa a referirse a una $3^{\mathrm{a}}$ persona general y adquiere él mismo un tono proverbial ("los que no pueden más se van"), reforzado por el introductor "siempre igual".

El drama y los contornos atribuidos a esas instancias personales van siendo construidos a lo largo de la letra mediante una sucesión de imágenes que iremos analizando a la par que observamos la versión creada en Brasil muchos años después.

Ya en el comienzo, la versión en portugués muestra dos diferencias que producen una representación del cuasi-personaje tú mucho menos autodestructiva. Por un lado, en la letra de Charly García, se atribuye al mismo tú esquivar su corazón y destrozar su propia cabeza. En la versión de Vianna, cierta ambigüedad sintáctica determina que el causador de esos procesos puede ser a febre de um sábado azul e um domingo sem tristezas, y el tú esté en un papel de experimentante ${ }^{4}$. Por otra parte, la imagen de "destrozar" la cabeza pasa a ser de certezas destruidas.

En función de lo primero, en la letra argentina el tú / personaje aparece más centrado sobre sí, su relación con el entorno es de separación. Una huella de esa escasa vinculación es la discontinuidad sintáctica entre las dos frases nominales del inicio (La fiebre de un sábado azul y un domingo sin tristezas) y la cláusula que les sigue. En la versión brasileña se registra una interacción en que elementos del entorno son activos para una alienación del ser en relación con sí mismo. En la letra en español también está afectada en cierta medida la integración entre dimensiones del ser, pero es el propio personaje quien aparece representado manipulando las "partes". Si "esquivas a tu corazón" aparece como una cierta desatención a sus propios sentimientos, "destrozas tu cabeza", en cambio, puede verse como una versión negativamente valorizada de la experiencia alucinatoria, el "reviente" como contracara del "viaje", si no como anticipación "literal"

\footnotetext{
${ }^{4}$ En efecto, podemos interpretar "a febre te esquiva" o, siguiendo una concordancia posible en algunas variedades del portugués brasileño, "(você / tu) te esquiva". No ignoramos que interviene en esa transformación el régimen pronominal del verbo esquivar(-se) en portugués. Sin embargo, como ya anticipamos en 2.2, esas condiciones no explican el resultado, ya que habría muchas paráfrasis posibles que mantendrían un papel de agente para el $t u ́$.
} 
del suicidio. Y aquí entra lo segundo, destrói tuas certezas, que introduce una dimensión de conocimiento que no estaba en juego, al menos de esa manera, en la letra de García, y refuerza la asimetría entre el tú y el yo en cuanto al saber. El tú interpelado y puesto en escena en la letra argentina es agente de su propia devastación; en ese sentido, aún en su miseria humana, es compacto. Su émulo en la versión brasileña evidencia en su contorno la acción del afuera. El primero parece "decidir" arrasar con su propia mente, pero no le ha pasado que ésta se le escape, como ocurre al segundo.

En las estrofas segunda y tercera se expone el conflicto mediante un gesto narrativo en que el tú se acerca más a la condición de personaje. Se lo relaciona con el ámbito de la creación musical y en general, como anticipamos, con valores compartidos en el campo del rock. Pero de entre esos valores, el de la autenticidad parece afectado por algunos de los cambios que se le atribuyen: cambiar de música, de ideas, de color. Son las estrofas que en la versión de Vianna siguen el camino de una traducción casi literal. Algunas excepciones son "gris ciudad" por cinzas 5 y "fronteras", que en la Argentina de 1979 remitía a los muchos exilios y autoexilios $^{6}$, por bandeiras. Además, no suena en la versión brasileña, en ningún momento, el reloj de fondo.

Pero es en la cuarta estrofa que se produce la transformación más significativa en cuanto a la enunciación, acompañada, como veremos, por algunas otras marcas congruentes. En la letra en español, hasta los bang, se mantiene la estructura enunciativa que ya describimos: un yo que habla a / sobre un tú / personaje: "Y llevas el caño a tu sien...". En cambio, en la letra en portugués se produce ahí una notable ambigüedad al respecto, posibilitada por el funcionamiento del portugués brasileño, pero que también podría, en esa lengua, haber sido evitada con diferentes procedimientos que diesen a los versos univocidad en la referencia personal. De hecho, hay tres maneras posibles de leer esa referencia:

\footnotetext{
5 En portugués, la palabra cinzas puede equivaler a, en español, “cenizas", pero como adjetivo y en singular, cinza, en portugués, es también el nombre del color gris.

${ }^{6}$ Varios de los miembros de Seru Giran venían de un autoexilio precisamente en Brasil, donde de hecho empezó a formarse la banda.
} 
a) El yo locutor le habla al tú, informando lo que el tú hace (la misma de la letra en español): [eu vejo que você] levanta o cano outra vez e aperta...

b) El yo cambió de perspectiva y muestra al personaje como $3^{\mathrm{a}}$ persona, informando lo que esa persona hace: [eu vejo que ele] levanta o cano outra vez e aperta...

c) El yo le habla al tú indicándole lo que debe hacer: [eu peço / ordeno a você:] levanta o cano outra vez e aperta...

Nótese que la posibilidad (a), que corresponde a la de la letra de García, es la menos disponible, en el portugués brasileño, para esa formulación, ya que para producir esa referencia, tendería a retomarse pronominalmente el sujeto: Você levanta o cano outra vez.... Esa ocurrencia de você sería, además, armónica con la estructuración de la tercera estrofa, con la cual guardaría paralelismo. Y en el lugar donde podría estar aparece un então, que permite tanto una lectura temporal (nesse momento), que se acercaría al valor de conector narrativo del "Y..." que encabeza la estrofa en castellano, como una interpretación consecutiva.

Creemos que esa estructuración tiene efectos en tres órdenes. Por una parte, su ambigüedad en cuanto al tipo de enunciación (¿narración o apelación?) consolida la disposición de evaluador-juez que ya atribuimos al yo locutor, así como su lugar de saber, reforzado por el posible valor explicativo de então. Por otra parte, debilita más aún lo autodestructivo en la representación del tú, y da más primacía al entorno por descompactar el cierre del ser sobre sí. A ese segundo efecto contribuye también la diferencia entre "ves todo el mar en primavera" y vê um céu de primavera, imagen que, dada la ambigüedad referencial, puede incluso no surgir, como visión, del mismo ser. Y por último, pero no menos importante, desestabiliza el carácter "omnisciente" del locutor-evaluador y crea un nuevo espacio personal. Ese espacio es una modalidad intermedia entre el centro absoluto de escena que el tú / personaje ocupa en las tres primeras estrofas y su total disolución, después de los "bang", en una persona general. En la letra argentina hay entre ambas situaciones un corte abrupto, $\mathrm{y}$ en la versión brasileña aparece ese lugar de transición que es extremamente inestable, ya que oscila entre el de un personaje pleno y el de un interlocutor. 
El conjunto de las transformaciones enunciativas en la versión brasileña apunta a la configuración de un contorno para el tú-personaje menos compactamente delimitado que en la versión argentina. Considerando que el contorno, como todo proceso de determinación, resulta del embate entre lo que se recorta y lo que queda afuera, observamos la versión otra como oportunidad de ver algo de lo residual, constitutivo, del primer tallado. La transposición brasileña realiza sus propias exclusiones pero también recoge lascas que cayeron de la primera. Destacamos la posibilidad latente para el locutor y, por incorporación, también para el interlocutor-oyente, de prever o hasta regir los movimientos del ser en escena. Combinación, en la voz, de la empatía con la víctima y la mirada del victimario. Un goce específico del lugar disidente que en el rock argentino sólo emergerá años después, revestido de un cierto cinismo, en los dúctiles enunciadores escenificados por Los Redondos ${ }^{7}$.

\section{BUSCANDO UN SENTIDO A TODO ESTO}

Nos ocuparemos ahora de un recorrido en sentido inverso: una composición brasileña reformulada por una banda argentina. "El tiempo no para" es parte de la etapa solista de Cazuza, considerado uno de los más grandes letristas del rock de Brasil, con fuertes lazos poéticos con tradiciones anteriores de la canción urbana.

En la letra de ese clásico, el centro de escena es ocupado por un yo que realiza un casi manifiesto sobre su lugar en el mundo. En varios momentos se interpela a un tú, que, sobre todo en la última estrofa, puede verse como generalizador (Te chamam de ladrão, de bicha, maconheiro...). En la misma estrofa aparece también una tercera persona general ${ }^{8}$ que

\footnotetext{
${ }^{7}$ Patricio Rey y los Redonditos de Ricota. Banda de rock argentina de las décadas del 80 y el 90, de marcadísima singularidad, principal exponente del underground. en el país. El artículo citado de Monteleone se centra en el análisis de su poética.

${ }^{8}$ Utilizaremos las denominaciones "persona general" y "generalizador", empleadas entre otros por Fernández Ramírez (1987), porque rechazamos las de "indeterminación del sujeto" o "impersonalidad" que se encuentran en algunos espacios de la reflexión gramatical sobre esas formas. La primera, porque creemos que es imposible la no determinación en el discurso: inclusive la indefinición y la genericidad son modos de determinación. La segunda, porque desde el punto de vista sintáctico, hay sujeto en todos los casos.
} 
resume la figuración opuesta a la del yo, construida a lo largo de toda la canción a partir de la imagen de correr na direção contrária y otras que le siguen y que presuponen una adversidad activa. Esa persona general opresora es relacionada en determinado momento con los que detentan poder sobre el país al punto de poder transformarlo en un puteiro (prostíbulo). En las condiciones impuestas por ese poder, restricciones que no ofrecen escapatoria (é matar ou morrer), un "nosotros" va conformando su condición: e assim nos tornamos brasileiros. Si bien a partir de la aparición de ese "nosotros" el foco de la letra se desplaza hacia esas formas generalizadoras, la perspectiva dominante es la del yo locutor. Ese ser, como en otras composiciones del género, aparece dotado de visión que otros no tienen y adquiere un tono proverbial en la aserción del estribillo, repetido en el cierre y que también da título al tema: o tempo não pára.

La banda argentina Bersuit Vergarabat grabó la composición en su primer LP. Cazuza era, y todavía es, casi un desconocido en Argentina, y Bersuit recién comenzaba a darse a conocer. La versión de $O$ tempo não pára, si bien siempre fue presentada evidenciando su proveniencia (en muchas ejecuciones en vivo el estribillo se ha cantado en portugués) muestra en un punto un intento de reubicación de la escena en un nuevo contexto nacional. En efecto, assim nos tornamos brasileiros fue traducido como "así nos hacemos argentinos", en lo que más parece una adopción que un cambio: identificar los mecanismos de opresión y corrupción como semejantes a través de las fronteras nacionales. Dejando de lado ese detalle, podemos decir que la adaptación argentina muestra un notable trabajo de adhesión a la propuesta de una composición de partida, que contiene momentos de una elaboración poética nada simple.

Sin embargo, vemos que en esa adaptación se produce un conjunto de desplazamientos por medio de los cuales el locutor realiza un trabajo que denominaremos sobredemarcación. La letra de Cazuza expone de manera contundente un conflicto, incluso representable espacialmente (correr na direção contrária), entre la perspectiva en que el yo se incluye y la del poder que aparece como fuerza opuesta. Intentaremos mostrar en nuestro análisis que si la separación entre el espacio de una fuerza y de otra puede verse, en Cazuza, como un trazado discontinuo pero recuperable, en 
la versión de Bersuit es como si el mismo se remarcase con una línea ostensiva que distribuye todas las entidades personales inequívocamente de un lado o del otro. Ese trabajo va acompañado por un cierre, realizado sobre todo mediante el agregado de conectores, de relaciones semánticas que en la letra de Cazuza se encuentran menos definidas. Desarrollaremos nuestra explicación siguiendo la progresión de la letra.

En el comienzo, la imagen del yo disparando contra el sol es seguida, en la letra de Cazuza, por la formulación sou forte, sou por acaso. En "disparo contra el sol con la fuerza del ocaso", si la fuerza atribuida al yo se mantiene o hasta se realza, ya que el ocaso es la desaparición del sol, se elimina, en cambio, la tensión entre forte y por acaso, expresión esta última que remite a lo casual, a lo no motivado. En la misma línea, vemos la transposición de mágoa (rencor) por "magia" como parte de la construcción de una imagen de fortaleza. Creemos que aunque la magia no es mostrada como una herramienta eficaz, no deja ser un atributo que confiere algo de especial al ser que se construye en ese inicio de la versión en castellano, dibujado sin la herida de ser por acaso. Así, el cambio en el modo de conexión con lo que sigue parece hacerse necesario. Donde simplemente teníamos la afirmación. Eu sou um cara, sin conector, tenemos una formulación fuertemente contrastiva, "pero sólo soy un hombre más". La restricción "sólo uno más" va en el sentido de la reformulación, en la letra de Cazuza, unos versos después: Eu sou mais um cara. Pero la construcción adversativa es realmente un agregado de la versión argentina: la fuerza y la magia no son suficientes para el combate. Con la misma linealidad con que se construyó el personaje, se deja "constancia" del alcance de su fuerza y se clausuran otras relaciones posibles, de no oposición, entre la imagen inicial y ser um cara $^{9}$.

Luego de la imagen ya mencionada de correr en dirección contraria, tenemos:

sem pódio de chegada ou beijo de namorada.

Eu sou mais um cara sin podio de llegada y mi amor me corta la cara, porque soy sólo un hombre más.

\footnotetext{
${ }^{9}$ Relaciones causales, por ejemplo: minha metralhadora cheia de mágoas [porque] eu sou um cara cansado de correr na direção contrária.
} 
La simple inexistencia (genérica) de una novia se trasforma en el rechazo por parte de una pareja específica. Y el hecho de ser "sólo un hombre más" pasa a ser causa de ese rechazo. El amor abandonador, que esperaba algo más que sólo un hombre, es puesto fuera del espacio del yo. Enseguida, se introduce una nueva relación semántica, causal, que cierra la interpretación. Por ser sólo un hombre, la falta de gloria (podio de llegada) lleva al abandono, a pesar de tratarse de un ser dotado de fuerza y potencial magia.

En la estrofa siguiente, conectada, en ambas letras, como adversativa en relación con la anterior, se relativiza la disparidad de fuerzas: el yopersonaje niega estar derrotado, pensamiento atribuido a un tú que no parece identificable como otro personaje, sino un modo de, entre las diferentes formas de generalización (se alguém pensar, se pensarem, si se piensa, si piensan), apuntar al virtual interlocutor de la proclama. La réplica es saiba que ainda estão rolando os dados, vertida como "quiero que sepas que me la sigo jugando". Comparando las dos construcciones empleadas, resulta bastante diferente el involucramiento representado para el ser que toma voz en el yo. El juego continua, y en la aserción en portugués están dados, por contexto, la participación y el riesgo. Pero éste está mucho más sujeto al devenir externo que en "me la sigo jugando", expresión de arrojo que involucra una dimensión mucho más íntima y tendiente a la representación de un individuo: el ser está en el centro del juego, es a la vez su disparador y su objeto.

Algunos versos después, en la imagen de la piscina, se interpela a otro tú, este mucho más singularizable:

A tua piscina está cheia de ratos, tuas idéias não correspondem aos fatos.
Y tu cabeza está llena de ratas,

te compraste las acciones de esta farsa.

En la versión argentina es más nítida la expulsión del tú hacia el campo de lo que el yo-personaje aparece combatiendo desde el inicio de la letra. La modulación de Cazuza en el canto es verdaderamente asqueada, pero en su letra las ratas se representan en el ámbito de las posesiones del ser interpelado, no en el de su personalidad ("cabeza"). Además, lo que puede verse como una equivocación (tuas idéias não correspondem aos 
fatos) aparece como adhesión a un engaño deliberado ("farsa"), el error se transforma en estafa.

El siguiente desplazamiento que destacamos, en la estrofa posterior, se refiere a cómo "emplea sus días" la figura central: procurando uma agulha no palheiro / "buscando un sentido a todo esto". La diferencia va en el mismo camino de construir un yo-personaje estabilizado en relación con el entorno. Análogamente a lo que observábamos en el caso de "Viernes 3 AM" para la disposición del ser en escena, en la letra brasileña, buscar una aguja en un pajar parece mostrar una tarea infructuosa por parte de un ser desorientado. En la versión argentina, se observa una disposición de propósito, un impulso de control sobre el entorno, que puede resultar igualmente inútil, pero muestra el espacio del yo-personaje como racionalizado. Incluso, como huella de la transposición de la letra a la discursividad de otro espacio lingüístico-nacional, "buscando un sentido a todo esto" puede verse como meta-enunciación que describe, impensadamente, la tarea desplegada por el enunciador-reformulador: el intento de control de las posibilidades semánticas, insertando en la letra numerosas señales que orienten su interpretación.

En la última estrofa antes de la repetición del estribillo, un nuevo tú generalizador es reemplazado por un "nosotros": Te chamam de ladrão, de bicha, maconheiro / "Nos tildan de ladrones, maricas, faloperos". La perspectiva es empática, se le habla a quien comparte el mismo lugar de oprimido. En ese sentido, la segunda persona, en la letra de Cazuza, muestra movilidad respecto de la orientación argumentativa de la voz instalada como yo, ya que en las dos apariciones anteriores la relación es de oposición polémica. No ocurre lo mismo en la versión de Bersuit, donde se produjo una separación, como vimos, mucho más tajante en relación con el tú. Así, el "nosotros", que ya apareció en "así nos hacemos argentinos" y está indisolublemente ligado al yo-personaje, es convocado hacia el lugar generalizador. Por último, uniendo esa afirmación con la que sigue (Transformam um país inteiro num puteiro...), encontramos en la letra argentina un agregado que explicita el contraste deducible en el original: " $y$ ellos sumergieron un país entero...". De ese modo, los espacios opuestos quedan sobredemarcados, y cada ser representado ubicado "en su lugar" en relación con el personaje central, en este caso, aparentemente, no sujeto a nada que, en el plano del enunciado, desdibuje su contorno. 


\section{CONCLUSIONES}

Las composiciones de las que nos hemos ocupado recogen en su dialogismo, de diferentes maneras, polémicas en el campo del rock, en toda su extensión mundial, sobre la necesidad de transformar la sociedad y la vida cotidiana, y la posibilidad / imposibilidad de hacerlo, así como sobre el alcance, individual o colectivo, de esas transformaciones. Ni "Viernes 3 AM" ni O tempo não pára se encuadran en el rock de visión revolucionaria ni en sus desdoblamientos utopistas: a pesar de la diferencia de 9 años entre sí, ambas son claramente pos-hippismo y pos-Vietnam, y en su materialidad resuena la desazón generacional que se expresó mediante el punk y tantas otras manifestaciones de fines de los 70' y comienzos de los 80 '.

Analizamos a lo largo de este artículo, en las dos letras y sus versiones, la construcción y el tallado de dos seres, uno de ellos en segunda persona, construido por una voz, y otro en primera persona, construido por y en la voz. Ambos representados en un entorno de adversidad en el que alcanzan diferentes grados de heroicidad. Y aunque en ambos se advierten aspectos del bagaje ideológico ligado al decir roquero, en el primer caso la relación del locutor con el ser es por momentos polémica, y en el segundo, de plena confluencia en una misma voz y posicionamiento.

Nos propusimos observar, en sus transposiciones a la otra lengua y a la otra discursividad, desplazamientos en los contornos trazados para esas entidades personales. Si podemos identificar un movimiento relativamente repetido, fue el de integración del ser sobre sí en la producción del rock argentino y de permeabilidad con el entorno en las letras brasileñas. Así, en "Viernes 3 AM" se representa la derrota de un sueño de trasformación, y la autodestrucción es la expresión de esa derrota, levemente desplazada, en la versión brasileña, a una desestructuración del ser en el entorno. En O tempo não pára, la derrota se refuta en la voz de un ser que resiste la adversidad desde un lugar de preeminencia, pero que no excluye la desorientación y el reconocimiento de un devenir (o acaso, o rolar dos dados), que se le escapa. En la lectura desde Argentina, la refutación de la derrota se desliza hacia una proclamación de la perspectiva personal ("me la sigo jugando") y de su intento de control sobre el entorno hostil. 
No es el optimismo o el pesimismo lo que las diferencia, como podría pensarse a partir de conocidos estereotipos. Los rock (y, en general, la música popular) de ambos países han cantado victorias, derrotas, esperanza y descrédito en el diálogo polémico del campo del que forman parte en el mundo. En ambos se han diseñado héroes exultantes y melancólicos, desgarrados y apacibles. Lo que parece marcar una tendencia diferenciadora es la expectativa para su tallado, el juego que otorga máscaras a la voz disidente en posicionamientos análogos de resistencia.

\section{REFERENCIAS}

BENVENISTE, É. Problemas de lingüistica general. Vol. 2. México: Siglo XXI, 1971.

BOURDIEU, P. O poder simbólico. Rio de Janeiro: Ed. Bertrand Brasil, 1989.

CINTRÃO, H. Gilberto Gil e Haroldo de Campos: Inconfluências, transcriação da canção. Revista de Letras, v. 47, n.1, p. 129-153, 2007.

DÍAZ, C. Libro de viajes y extravios: un recorrido por el rock argentino 19651985. Córdoba: Narvaja Editor, 2005.

DUCROT, O. El decir y lo dicho. Buenos Aires: Edicial, 2001.

FOUCAULT, M. La arqueología del saber. Buenos Aires: Siglo XXI, 2007.

FERNÁNDEZ RAMÍREZ, S. Gramática española. Vol. 4. El verbo y la oración. Madrid: Arco Libros, 1987.

FANJUL, A. Delimitación enunciativa de héroes en letras de música urbana de Brasil y Argentina. In: ACTAS DEL XIV CONGRESO DE ALFAL, Monterrey, Anales. Publicado en CD-ROM sin números de página, 2005.

GREGOLIN, M. Foucault e Pêcheux na análise do discurso: diálogos e duelos. São Carlos: Ed. Claraluz, 2004.

GUIMARÃES, E. Semântica do acontecimento. Campinas: Pontes, 2005. . Enunciação e história. In: GUIMARÃES, E. (Org.) História e sentido na linguagem. Campinas: Pontes, 1989. p. 71-79.

JAKOBSON, R. Lingüistica y comunicación. São Paulo: Cultrix, 2001.

MAINGUENEAU, D. Cenas da enunciação. São Paulo: Parábola, 2008.

. O contexto da obra literária. São Paulo: Martins Fontes, 2001

MONTELEONE, J. El infierno encantador. Violencia y poesía del rock. Espacios de crítica y producción, n. 11, p. 29-33, 1992. 
ORLANDI, E. Terra à vista. São Paulo: Cortez, 1990. . Discurso e leitura. São Paulo: Cortez, 1988.

PÊCHEUX, M. Leitura e memória. Projeto de pesquisa. In: ORLANDI, E. (Org.). Análise do discurso. Michel Pêcheux. Pontes: Campinas, 2011. p. 141-150.

. O discurso: estrutura ou acontecimento. Campinas: Pontes, 2002. . Só há causa daquilo que falha ou o inverno político francês. O início de uma retificação. In: PÊCHEUX, M. Semântica e discurso. Uma crítica à afirmação do óbvio. Campinas: Ed. da UNICAMP, 1997. p. 269-281.

TATIT, L. Elementos para análise da canção popular. Cadernos de Semiótica Aplicada, v. 1, n. 2, p. 7-24, 2003.

\section{COMPOSICIONES MUSICALES REFERIDAS}

Bersuit Vergarabat: "El tiempo no para". Versión: Gustavo Cordera y Carlos Martín. En Y punto, Polydor, 1991.

Cazuza: "O tempo não pára”. Autores: Arnaldo Brandão y Cazuza. En O tempo não pára, Polygram, 1988.

Paralamas do Sucesso: "Viernes 3 AM". Versión: Herbert Vianna. En Hey Na Na. Emi Music, 1998.

Seru Girán: "Viernes 3 AM". Autor: Charly García. En: La grasa de las capitales. D \& D producciones fonográficas, 1979.

ANEXOS

Letras de las composiciones analizadas

"Viernes 3 AM" Seru Girán

Autor: Charly García (1979)

La fiebre de un sábado azul

y un domingo sin tristezas.

Esquivas a tu corazón

y destrozas tu cabeza.

Y en tu voz, sólo un pálido adiós.

Y el reloj en tu puño marcó las tres.
"Viernes 3 AM" Paralamas do Sucesso Versión: Herbert Vianna (1998)

A febre de um sábado azul

e um domingo sem tristezas

te esquiva do teu próprio coração

e destrói tuas certezas

E em tua voz, só um pálido adeus.

E o relógio no teu punho marcou as três. 
El sueño de un sol y de un mar

y una vida peligrosa

cambiando lo amargo por miel

y la gris ciudad por rosas

te hace bien, tanto como hace mal

te hace odiar, tanto como querer y más.

Cambiaste de tiempo y de amor

y de música y de ideas.

Cambiaste de sexo y de Dios

de color y de fronteras.

Pero en sí, nada más cambiará,

y un sensual abandono vendrá, y el fin.

Y llevas el caño a tu sien

apretando bien las muelas.

Y cierras los ojos y ves

todo el mar en primavera.

Bang, bang, bang.

Hojas muertas que caen.

Siempre igual,

los que no pueden más

se van.

\section{“O tempo não pára" Cazuza}

Autores: Arnaldo Brandão/Cazuza (1988)

Disparo contra o sol, sou forte, sou por acaso.

Minha metralhadora cheia de mágoas.

$\mathrm{Eu}$ sou um cara.

Cansado de correr na direção contrária, sem pódio de chegada ou beijo de namorada, eu sou mais um cara.

Mas se você achar que eu tô derrotado, saiba que ainda estão rolando os dados, porque o tempo, o tempo não pára.

Dias sim, dias não, eu vou sobrevivendo sem um arranhão da caridade de quem me detesta.
O sonho de um céu e de um mar

e de uma vida perigosa

trocando o amargo pelo mel

e as cinzas pelas rosas

te faz bem tanto quanto mal

faz odiar tanto quanto querer demais

Você trocou de tempo e de amor

e de música e de idéias.

Também trocou de sexo e de Deus

e de cor e de bandeiras.

Mas em si nada vai mudar

e um sensual abandono virá, e o fim.

Então levanta o cano outra vez

e aperta contra a testa.

E fecha os olhos e vê

um céu de primavera.

Bang, Bang, Bang.

Folhas mortas que caem.

Sempre igual,

os que não podem mais

se vão

\section{"El tiempo no para" Bersuit Vergarabat} Versión: Gustavo Cordera/Carlos Martín (1991)

Disparo contra el sol con la fuerza del ocaso.

Mi ametralladora está llena de magia, pero soy sólo un hombre más.

Cansado de correr en la dirección contraria, sin podio de llegada y mi amor me corta la cara, porque soy sólo un hombre más.

Pero si pensás que estoy derrotado, quiero que sepas que me la sigo jugando, porque el tiempo, el tiempo no para.

Unos días sí, otros no, estoy sobreviviendo sin un rasguñon, por la caridad de quien me detesta. 
A tua piscina está cheia de ratos, tuas idéias não correspondem aos fatos, e o tempo não pára.

Eu vejo o futuro repetir o passado, eu vejo um museu de grandes novidades, o tempo não pára.

Eu não tenho data pra comemorar, às vezes os meus dias são de par em par, procurando uma agulha no palheiro. Nas noites de frio é melhor nem nascer; nas de calor, se escolhe: é matar ou morrer, e assim nos tornamos brasileiros.

Te chamam de ladrão, de bicha, maconheiro. Transformam o país inteiro num puteiro, pois assim se ganha mais dinheiro.
Y tu cabeza está llena de ratas, te compraste las acciones de esta farsa, y el tiempo no para.

Yo veo el futuro repetir el pasado, veo un museo de grandes novedades, y el tiempo no para.

Yo no tengo fechas para recordar, mis días se gastan de par en par buscando un sentido a todo esto. Las noches de frío es mejor ni nacer, las de calor se escoge matar o morir, y así nos hacemos argentinos.

Nos tildan de ladrones, maricas, faloperos, y ellos sumergieron un país entero, pues así se roba más dinero.

\section{Recebido em: 19/11/12. Aprovado em: 19/07/13.}

Title: Carving and boundaries: transcribed compositions between the Brazilian and the Argentinian rock

Author: Adrián Pablo Fanjul

Abstract: Here we approach some configurations in the representation of several types of personal entities in enunciation, in a comparison between Brazilian and Argentinean discursivities. The cases in study are poetic-musical compositions in the rock music, transcribed from one country to the other. We work with a theoretical and methodological reference based on the enunciativediscourse analysis. We observed the changes which are produced in the passage of the compositions from one discursivity and language to the other, regarding the contour of the figures and voices represented in the enunciation. We found in the Argentinian productions a tendency to reinforce these contours while a higher permeability to the represented surroundings was observed in the Brazilian productions.

Keywords: Person in enunciation. Rock discursivity. Comparative studies between Brazil and Argentina. 
Título: Entalhe e demarcação: composições transpostas entre o rock do Brasil e o da Argentina

Autor: Adrián Pablo Fanjul

Resumo: Abordamos, de modo comparativo entre discursividades brasileiras e argentinas, configurações para a representação de diversos tipos de entidades pessoais na enunciação. Os casos analisados são composições poético-musicais, enquadradas no campo do rock, transpostas de um país para o outro. Trabalhamos a partir de um referencial teórico e metodológico localizado na análise discursivo-enunciativa. Observamos as transformações produzidas na passagem das composições de uma discursividade e de uma língua para a outra, no que diz respeito ao contorno das figuras e das vozes representadas na enunciação. Encontramos, nas produções argentinas, uma tendência ao reforço desses contornos e, nas produções brasileiras, uma maior permeabilidade ao contexto representado.

Palavras-chave: Pessoa na enunciação. Discursividade no rock. Estudos comparados entre o Brasil e a Argentina. 